\title{
Preparation and investigation of mefenamic acid - polyethylene glycol - sucrose ester solid dispersions
}

\author{
IBOLYA FÜLÖP ${ }^{1}$ \\ ÁRPÁD GYÉRESI ${ }^{1}$ \\ LÓRÁND KISS ${ }^{2}$ \\ MÁRIA A. DELI \\ MIRCEA DUMITRU CROITORU ${ }^{1 *}$ \\ PIROSKA SZABÓ-RÉVÉSZ \\ ZOLTÁN AIGNER ${ }^{3}$ \\ ${ }^{1}$ University of Medicine and Pharmacy \\ Tîrgu Mureş, Faculty of Pharmacy \\ 540139, Tîrgu Mureş, Romania \\ ${ }^{2}$ Institute of Biophysics \\ Biological Research Centre \\ Hungarian Academy of Sciences \\ 6726, Szeged, Hungary \\ ${ }^{3}$ University of Szeged \\ Faculty of Pharmacy \\ Department of Pharmaceutical Technology \\ 6720, Szeged, Hungary \\ Accepted July 14, 2015
}

\begin{abstract}
Mefenamic acid (MA) is a widely used non-steroidal antiinflammatory (NSAID) drug. The adverse effects typical of NSAIDs are also present in the case of MA, partly due to its low water solubility. The aim of this study was to increase the water solubility of MA in order to influence its absorption and bioavailability. Solid dispersions of MA were prepared by the melting method using polyethylene glycol 6000 and different types (laurate, D-1216; palmitate, P-1670; stearate, S-1670) and amounts of sucrose esters as carriers. The X-ray diffraction results show that MA crystals were not present in the products. Dissolution tests carried out in artificial intestinal juice showed that the product containing $10 \%$ D-1216 increased water solubility about 3 times. The apparent permeability coefficient of MA across human Caco-2 intestinal epithelial cell layers was high and, despite the difference in solubility, there was no further increase in drug penetration in the presence of the applied additives.
\end{abstract}

Keywords: mefenamic acid, sucrose esters, PEG 6000, solid dispersion, Caco-2 cells

Mefenamic acid [MA, 2-(2,3-dimethylphenyl)aminobenzoic acid], an anthranilic acid derivative, is a widely used non-steroidal anti-inflammatory (NSAID) drug (1).

Regarding the pharmacokinetics of the drug, MA is absorbed from the small intestine (2), its bioavailability is about $90 \%$ but is influenced by the amount of water ingested with the drug in fasting subjects. The $t_{\max }$ is attained in $2-4$ hours, and steady-state concentration is reached in $2-3$ days $(2,3)$.

Like other NSAIDs, MA can cause serious gastrointestinal adverse effects (bleeding, ulceration) due to its mechanism of action (4) and acting as an irritant of the gastrointestinal mucosa (5).

MA belongs to class II of the biopharmaceutical classification system (BCS) - drugs with low solubility and high permeability; therefore, its oral bioavailability is determined by its dissolution rate in the gastrointestinal fluid and, consequently, it has variable absorp-

\footnotetext{
*Correspondence; e-mail: croitoru.mircea@umftgm.ro
} 
tion $(6,7)$. In the literature, there are different methods to enhance MA solubility and dissolution rate. The most commonly used techniques are the formation of inclusion complexes with several cyclodextrin derivatives (8-10) and preparation of solid dispersions (SD) with water soluble polymers (polyvinylpyrrolidone, PVP, or polyethylene glycol, PEG) (11) in binary and ternary systems with a disintegrant and Polysorbate 20, respectively (12). Solubility increase was achieved in both cases according to literature data, but there is no information regarding the effect of auxiliary substances on permeability. Auxiliary substances may negatively affect the permeability (13). The presence of hydroxy-propyl- $\beta$ cyclodextrin decreased the permeability of dexamethasone in a Caco-2 cell model and in the in situ single-pass rat intestinal perfusion model (14) while Polysorbate 80 decreased permeability of progesterone across an artificial dimethicone membrane (15). Polymers such as PEG 400 are also able to reduce the permeability of lipophilic drugs (16). PEG with higher molecular mass increases the permeability coefficient $\left(P_{\text {app }}\right)$ of indomethacin (17). The permeability-increasing effect of sucrose esters (SE) on Caco-2 cells was also demonstrated (18).

The aim of our work was to increase the water solubility of MA in order to reduce its gastrointestinal adverse effects (19) and the variability of absorption. Modification of the permeability of MA in different solid dispersions was also evaluated (solubility-permeability interplay). Ternary products were prepared with PEG 6000 and sucrose esters as carriers. Sucrose esters were chosen as ternary components because they can act as penetration enhancers along with their solubility increasing property. Sucrose esters are non-ionic surfactants $(20,21)$ and, due to their thermal behaviour (low melting point), can be used in preparation of solid dispersions made by the melting technique $(21,22)$. In this paper, beside the product preparation method, the solubility and permeability influencing properties of the obtained solid dispersions are presented.

\section{EXPERIMENTAL}

\section{Materials}

Mefenamic acid and all reagents were purchased from Sigma-Aldrich, Hungary, unless otherwise indicated. Laurate sucrose ester (D-1216, sucrose laurate) was of pharmaceutical grade, palmitate (P-1670, sucrose palmitate) and stearate (S-1670, sucrose stearate) sucrose esters were of analytical grade (Mitsubishi Kagaku Foods Co., Japan). PEG 6000 was supplied by Merck, Germany. All other reagents and solvents were of analytical grade.

\section{Product preparation}

Ternary products composed of MA, PEG 6000 and SE were prepared by the melting method. The SEs were dissolved (D1216) or suspended (P1670 and S1670) in the melted PEG $6000\left(80{ }^{\circ} \mathrm{C}\right)$. The temperature was increased to $110^{\circ} \mathrm{C}$, then the accurately weighed MA powder was added to the blend to dissolve under mixing for 20 minutes. The obtained mixtures were poured onto a cooled metal plate in a thin layer to cool quickly. The temperature of the cooled plate was contolled by a JULABO cryothermostate model F32 (JULABO model-F32, Labortechnik GmbH, Germany). The mixtures were kept at $-20{ }^{\circ} \mathrm{C}$ for 24 hours, then scraped off, pulverized in a mortar and passed through a $100-\mu \mathrm{m}$ sieve. The products were stored at room temperature until analysis. The composition of the products 
I. Fülöp et al.: Preparation and investigation of mefenamic acid-polyethylene glycol-sucrose ester solid dispersions, Acta Pharm. 65 (2015) 453-462.

is presented in Table I. All products contained $10 \%$ of MA, $5 \%$ or $10 \%$ of sucrose ester (D1216, P1670 and S167, shortened as D, P and S, respectively) and 85 or $80 \%$ of PEG 6000.

Table I. Composition of the studied products

\begin{tabular}{|c|c|c|c|c|}
\hline MA (\%) & & & PEG (\%) & Product code \\
\hline \multirow{6}{*}{10} & \multirow{2}{*}{ D-1216 } & 5 & 85 & D5 \\
\hline & & 10 & 80 & D10 \\
\hline & \multirow{2}{*}{ P-1670 } & 5 & 85 & P5 \\
\hline & & 10 & 80 & P10 \\
\hline & \multirow{2}{*}{ S-1670 } & 5 & 85 & S5 \\
\hline & & 10 & 80 & $\mathrm{~S} 10$ \\
\hline 10 & - & 0 & 90 & PEG \\
\hline
\end{tabular}

\section{Characterization of solid dispersions}

$X$-ray diffraction analysis. - X-ray diffraction (XRPD) analyses were conducted using a Rigaku MiniFlex ${ }^{\mathrm{TM}}$ II X-Ray diffractometer (Rigaku Co., Japan), where the tube anode was $\mathrm{Cu}$ with $K_{\alpha}=1.5405 \AA$. The data was collected using $30-\mathrm{kV}$ tube voltage and $15-\mathrm{mA}$ tube current in step scan mode $\left(4^{\circ} \mathrm{min}^{-1}\right)$. The instrument was calibrated using silicon.

In vitro dissolution studies and kinetic calculations. - Dissolution studies were performed in artificial gastric fluid (AGF, pH 1.2) and artificial intestinal fluid (AIF, pH 6.8) without enzymes, using the rotating paddle method according to Eur. Ph. - Pharma Test PTW-II, Germany (23), adapted to $100-\mathrm{mL}$ dissolution medium. Amounts of samples equivalent to $30 \mathrm{mg}$ MA were introduced into hydroxypropyl methylcellulose capsules and immersed into the dissolution medium at a rotation speed of $100 \mathrm{rpm}$ and temperature of $37^{\circ} \mathrm{C}$. Aliquots of $50 \mathrm{~mL}$ were collected periodically and replaced with fresh dissolution medium. After filtration the concentration of MA was determined spectrophotometrically (ATI UNICAM UV-VIS, spectrophotometer, USA) at $352 \mathrm{~nm}$ (AGF) and $288 \mathrm{~nm}$ (AIF). Measurements were performed in triplicate. Dissolution tests were conducted under non-sink conditions in order to evaluate the differences between the formulations. The mechanism of drug release was evaluated by different mathematical models offered by the DDSolver software (24). The best fit was chosen based on the adjusted coefficient of determination $\left(R^{2}\right.$ adj $)(25)$.

\section{Cell culture, viability and permeability assays}

The cell culture conditions and the methods for toxicity and permeability measurements in the case of MA and its products were described by our group previously (26). Briefly, for the cytotoxicity assays, Caco-2 human intestinal epithelial cells were cultured in 96-well plates in Dulbecco's modified Eagle's medium without phenol red containing $10 \%$ fetal bovine serum (Gibco, Invitrogen, USA). During the treatment period, the plates were placed on a horizontal shaker at $100 \mathrm{rpm}$. Tested formulations contained 1, 10, 30, 100, 300, 1000, $3000 \mu \mathrm{g} \mathrm{mL}^{-1} \mathrm{MA}$ as the final concentration. Cytotoxicity was evaluated by: (i) measuring the lactate dehydrogenase (LDH) enzyme activity from culture supernatant 
using a LDH detection kit (Roche, Switzerland), (ii) testing cell metabolic activity by measuring MTT dye [3-(4,5-dimethyltiazol-2-yl)-2,5-diphenyltetrazolium bromide] conversion, reflecting the number of viable cells. To study the permeability of MA in solid dispersions, human Caco-2 cells were cultured on Transwell filter inserts (polycarbonate membrane, $0.4-\mu \mathrm{m}$ pore size, $1.12 \mathrm{~cm}^{2}$ surface area, Corning Costar Co., USA) for 21 days. The transepithelial electrical resistance (TEER) of Caco-2 monolayers varied between 450 and 600 $\Omega \mathrm{cm}^{-2}$, indicating good barrier properties. The treatment solutions contained 3 or $100 \mu \mathrm{g}$ $\mathrm{mL}^{-1}$ MA dissolved in Ringer-Hepes buffer and MA penetration across cell layers was determined in the apical (donor) to basal (acceptor) direction for 1 hour. The concentrations of MA were determined both in the basolateral and apical compartments using a Merck HPLC system (consisting of a quaternary pump L-7100, auto sampler L-7200, column thermostat L-7360, DAD detector L-7455, interface L-7000, solvent degasser L-7612, HSM manager software) (Merck, Germany). The analysis was carried out at ambient temperature using a Purospher RP C18e (5 $\mu \mathrm{m}, 250 \times 4.6 \mathrm{~mm}$, Merck) column. Determinations were performed by isocratic elution at a flow rate of $1.5 \mathrm{~mL} \mathrm{~min}^{-1}$. The mobile phase composition consisted of $55 \% 20 \mathrm{mmol} \mathrm{L}^{-1}$ phosphate buffer $(\mathrm{pH} 6.5)$ and $45 \%$ acetonitrile. Volumes of $100 \mu \mathrm{L}$ were injected using the loop method; the detection wavelength was set at $281 \mathrm{~nm}$. Calculations were performed by measurement of peak areas.

The apparent permeability $\left(P_{\text {app }}\right)$ was calculated using the formula:

$$
P_{\text {app }}=\frac{\frac{d Q}{d t}}{A c_{0}}
$$

where $d Q / d t$ is the rate of drug permeation across the cells, $c_{0}$ is the donor compartment concentration at time zero and $A$ is the area of the cell monolayer $\left(1.12 \mathrm{~cm}^{2}\right)$.

All data presented are means \pm standard deviations. The values were compared using ANOVA followed by Dunnet's test using (GraphPad Prism 5.0 software, GraphPad Software Inc., USA). The changes were considered statistically significant at $p<0.05$. All experiments were repeated at least two times, the number of parallel samples varied between 3 and 8 .

\section{RESULTS AND DISCUSSION}

\section{X-ray diffraction analysis}

The XRPD patterns of the MA, P1670 and solid dispersions are represented in Fig. 1. MA exists in two polymorphic forms. Based on our previous DSC thermograms (9) and the XRPD peaks observed at 6.4, 16.0, 21.5 and $26.3^{\circ}(2 \theta)(27,28)$, the form I polymorph of MA was identified. The sharp, narrow peaks observed in the case of MA indicate its crystalline status. The diffractograms of pure PEG 6000 and P1670 showed broad peaks at 19.2, 23.3 and $21.36^{\circ}(2 \theta)$, respectively. The peaks related to MA were not present in the case of solid dispersions and the peaks of PEG 6000 are reduced and shifted to higher angles, indicating the amorphous state of the drug. In the case of solid dispersions, the peaks of PEG 6000 are predominantly present. Therefore, it can be confirmed that the active ingredient is predominantly molecularly dispersed in the carrier or amorphous. The relative degree of crystallinity $(R D C)$ was calculated at $16.5^{\circ}$ using the formula (29):

$$
R D C=\frac{R I_{\mathrm{SD}}}{R I_{\mathrm{MA}}}
$$




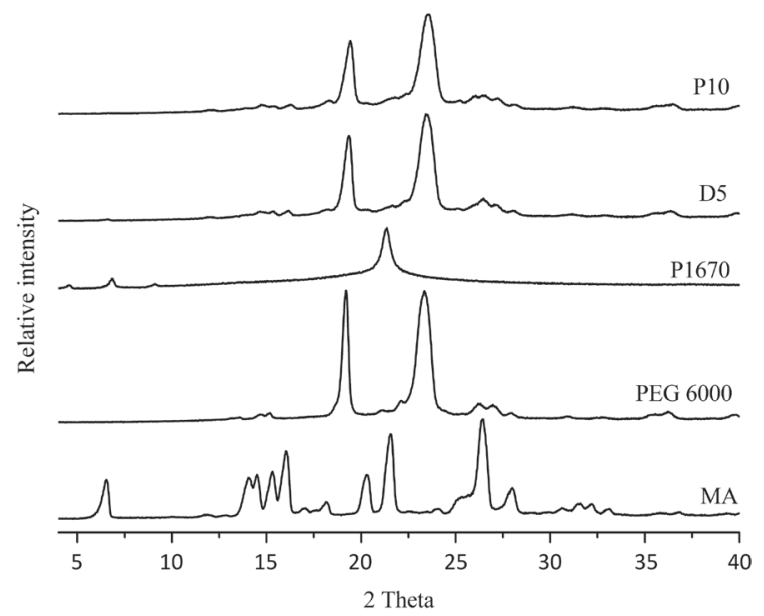

Fig. 1. XRPD patterns of the studied products (MA - mefenamic acid, P1670, PEG 6000 and solid dispersions D5 and P10 see (Table I).

where $R I_{\mathrm{SD}}$ is the peak height of the solid dispersion and $R I_{\mathrm{MA}}$ is the peak height of MA at the same angle. The RDC for P10 was 0.012 and 0.014, for D5 suggesting that only partially crystallized MA molecules are present in the products.

\section{Dissolution studies}

MA, a drug with an acidic character, dissolves slightly in AGF, especially its form I polymorph (27); after 120 minutes only $0.6 \%$ of MA was dissolved. In the case of ternary products the dissolution curves showed a peak after 15-30 minutes, indicating that supersaturation occured only when chiefly molecularly dispersed form was present, followed by recrystallization of the drug, which entailed a decrease in the amount dissolved. The best results were obtained with the S5 product, where $3.1 \%$ of MA was dissolved after 120 $\min$.

In AIF, $9 \%$ of MA was dissolved after 120 minutes (concentration of $2.70 \mathrm{mg}$ per 100 $\mathrm{mL}^{-1}$ was achieved). The amount of dissolved drug increased about 3 times (28.6 \%) 8.58 $\mathrm{mg}$ in $100 \mathrm{~mL}^{-1}$ ) in the product containing $10 \% \mathrm{D}-1216$ compared to pure MA. In the case of other studied products, the dissolution rate of MA proved to be lower. Solubility decreased in the following order: D10 $>$ S10 $>$ P10 $>$ D5 $>$ P5 $>$ S5 $>$ PEG. The dissolution profiles in AIF are represented in Fig. 2.

The mechanism of drug release is described by the Gompertz function:

$$
F=F_{\text {max }} \cdot e^{-\alpha e^{-\beta \log (t)}}
$$

where $F_{\max }$ is maximum dissolution, $a$ determines the undissolved portion at time $t=1$ (scale factor), and $\beta$ is the dissolution rate per unit time (shape factor) (30). The coefficients of determination were above 0.95 in all cases.

The Gompertz model is typically used for comparing release profiles of drugs with good solubility and intermediate release rates. This model has a steep increase at the 


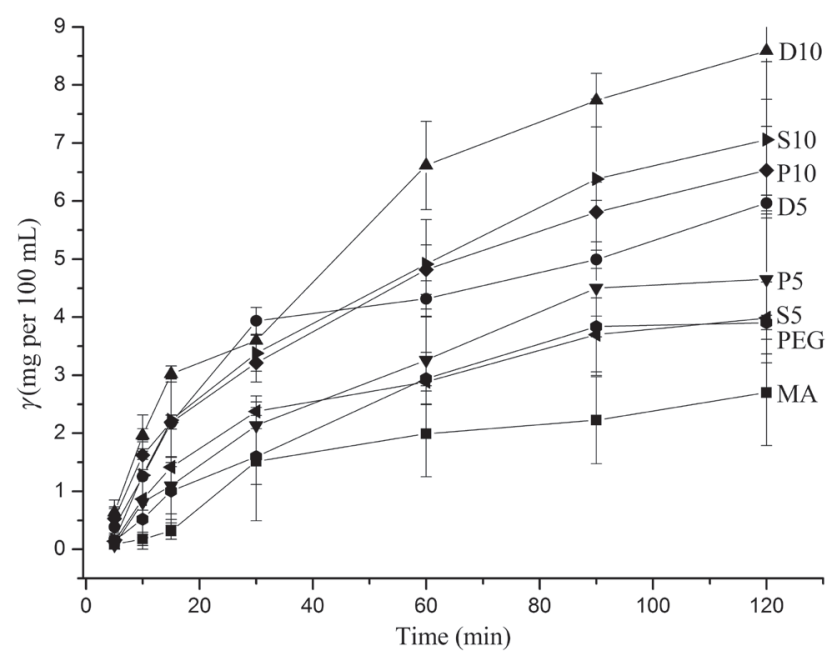

Fig. 2. Dissolution profiles of MA alone and in solid dispersions in artificial intestinal fluid (mean \pm $\mathrm{SD}, n=3)$.

beginning and converges slowly to the asymptotic maximal dissolution (27). In our case, after fast wetting of the matrix, a certain amount of MA dissolved fast; after that, the dissolution media became saturated in MA because of the non-sink conditions. Similarly to data shown in Fig. 2, D10 was the most efficient of the studied products in increasing the MA dissolution rate according to dissolution profile data (Table II) compared to the Gompertz model.

\section{Effects of mefenamic acid and formulations on the viability of Caco-2 cells}

MA was not toxic in concentrations lower than $100 \mu \mathrm{g} \mathrm{mL}^{-1}$ in both assays (MTT dye conversion and LDH release assays) but caused cell death at concentration of $1 \mathrm{mg} \mathrm{mL}^{-1}$ (Table III). Formulation containing only PEG 6000 did not change the toxicity pattern of the active ingredient. Among the formulations, those containing S-1670 (S5 and S10) showed the highest toxicity, which was increased ten times compared to MA and PEG. P-1670containing samples (P5 and P10) were less toxic than formulations with S-1670. The nontoxic concentrations of P-1670 were three times higher than that for S-1670; however, the concentrations killing cells were the same for samples S5, S10, P5 and P10. The best formulation was the D5 sample containing D-1216, where the non-toxic concentration was $100 \mu \mathrm{g}$ $\mathrm{mL}^{-1}$ and the toxic one was $300 \mu \mathrm{g} \mathrm{mL}^{-1}$.

\section{Effect of formulations on transepithelial electrical resistance in Caco-2 cells}

Caco-2 cell layers were treated by dilution of the samples containing $3 \mu \mathrm{g} \mathrm{mL} \mathrm{m}^{-1}$ of MA. After 1-hour treatment, the resistance of cell monolayers did not change; it remained in the range of the original $450-600 \Omega \mathrm{cm}^{-2}$ values. No significant differences were found in the resistance of cell monolayers treated with the products. 
I. Fülöp et al.: Preparation and investigation of mefenamic acid-polyethylene glycol-sucrose ester solid dispersions, Acta Pharm. 65 (2015) 453-462.

Table II. Dissolution kinetics of solid dispersions in AIF

\begin{tabular}{lcccc}
\hline Product & $\begin{array}{c}F_{\max } \pm \mathrm{SD} \\
\left(\mathrm{mg} \text { per } 100 \mathrm{~mL}^{-1}\right)\end{array}$ & $\begin{array}{c}\alpha \pm \mathrm{SD} \\
\left(\mathrm{min}^{-1}\right)\end{array}$ & $\begin{array}{c}\beta \pm \mathrm{SD} \\
\left(\mathrm{min}^{-1}\right)\end{array}$ & $R^{2}$ \\
\hline MA & $11.17 \pm 2.49$ & $223.20 \pm 203.28$ & $3.48 \pm 1.64$ & 0.9660 \\
PEG & $27.06 \pm 14.11$ & $88.12 \pm 139.25$ & $1.91 \pm 1.41$ & 0.9775 \\
D5 & $21.87 \pm 3.49$ & $21.95 \pm 20.75$ & $2.28 \pm 0.74$ & 0.9514 \\
D10 & $106.29 \pm 36.80$ & $5.98 \pm 0.44$ & $0.75 \pm 0.08$ & 0.9907 \\
P5 & $60.32 \pm 70.14$ & $11.89 \pm 4.96$ & $1.34 \pm 0.64$ & 0.9806 \\
P10 & $89.72 \pm 50.31$ & $6.10 \pm 0.59$ & $0.82 \pm 0.37$ & 0.9884 \\
S5 & $29.86 \pm 30.62$ & $48.47 \pm 41.30$ & $2.76 \pm 1.85$ & 0.9612 \\
S10 & $60.55 \pm 33.04$ & $8.84 \pm 3.67$ & $1.17 \pm 0.51$ & 0.9839 \\
\hline
\end{tabular}

$F_{\max }$ - maximum dissolution; $a$ - undissolved portion at time $t=1$ (scale factor); $\beta$ - dissolution rate per unit time (shape factor)

Table III. Toxic effects of MA and its products on Caco-2 human epithelial cells after 24 hours

\begin{tabular}{|c|c|c|c|c|}
\hline \multirow[b]{2}{*}{ Sample } & \multicolumn{2}{|c|}{ MTT dye conversion $^{a}$} & \multicolumn{2}{|c|}{ LDH release } \\
\hline & $\begin{array}{c}\mathrm{TC}_{0} \\
\left(\mu \mathrm{g} \mathrm{mL}^{-1}\right)\end{array}$ & $\begin{array}{c}T C_{100} \\
\left(\mu \mathrm{g} \mathrm{mL}^{-1}\right)\end{array}$ & $\begin{array}{c}\mathrm{TC}_{0} \\
\left(\mu \mathrm{g} \mathrm{mL}^{-1}\right)\end{array}$ & $\begin{array}{c}T C_{100} \\
\left(\mu \mathrm{g} \mathrm{mL}^{-1}\right)\end{array}$ \\
\hline MA & 100 & 1000 & 100 & 1000 \\
\hline PEG & 100 & 1000 & 100 & 1000 \\
\hline D5 & 100 & 300 & 100 & 300 \\
\hline D10 & 30 & 300 & 30 & 300 \\
\hline P5 & 30 & 100 & 30 & 100 \\
\hline P10 & 30 & 100 & 10 & 100 \\
\hline S5 & 10 & 100 & 10 & 100 \\
\hline S10 & 10 & 100 & 10 & 100 \\
\hline
\end{tabular}

${ }^{\mathrm{a}} \mathrm{TC}_{0}$ - the highest non-toxic concentration (no toxicity); $T C_{100}-100 \%$ toxic concentration

\section{Permeability measurement across Caco-2 cells}

The permeability coefficient of MA was $49 \times 10^{-6} \mathrm{~cm} \mathrm{~s}^{-1}$, reflecting its high permeability rate and lipophilic character (Fig. 3).

PEG 6000 and sucrose esters could not further increase the permeability of MA at the tested low concentration $\left(3 \mu \mathrm{g} \mathrm{mL}^{-1}\right)$, when the active ingredient was already completely solubilized (Fig. 4). The permeability coefficient of MA decreased statistically significantly in products D5 and P10 $(p<0.05)$, since the hydrophilic auxiliary substances reduced the permeability of MA. The analysis was repeated in the case of MA, D5, D10 and PEG products using $100 \mu \mathrm{g} \mathrm{mL}^{-1} \mathrm{MA}$ in the donor compartment. Similarly to the first set of experiments, D10 and PEG did not cause any significant change in the permeability of MA, while D5 drug penetration decreased significantly $(p<0.05)$. 


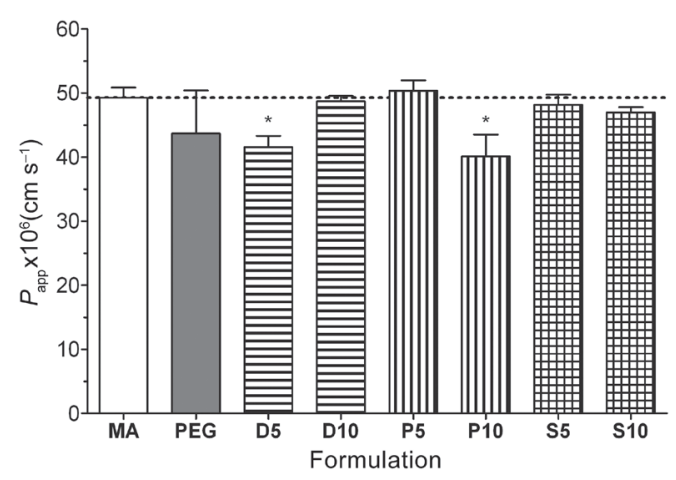

Fig. 3. Permeability of mefenamic acid measured on Caco-2 epithelial cell layers after 1-hour treatments with different formulations $\left(P_{\text {app }}-\right.$ apparent permeability coefficient, ${ }^{*}$ statistically significant differences between the MA and the formulations, $p<0.05$ ).

\section{The relationship between $M A$ solubility and permeability}

The relationship between MA solubility and permeability and its products with D-1216 is shown in Fig. 4. The solubility rate increased in this order: MA-PEG $<$ D5 $<$ D10. The rate of change of $P_{\text {app }}$ (at $3 \mu \mathrm{g} \mathrm{mL}-1 \mathrm{MA}$ ) did not correlate with the solubility increment; neither ascendant nor descendant tendencies could be observed. This can be explained by the high permeability of MA and by the difference in $\mathrm{pH}$ values applied in the AIF ( $\mathrm{pH} 6.8$ ) and permeability ( $\mathrm{pH}$ 7.4) studies.

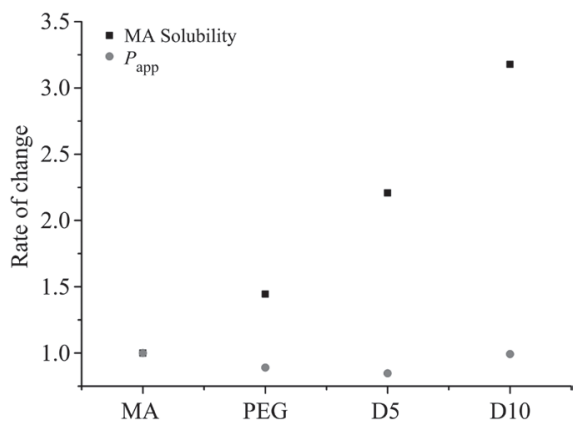

Fig. 4. Relationship between MA solubility and $P_{\text {app }}$ in the case of D-1216 containing products (D5 and D10) and the binary product (PEG) (the rate of change was calculated by dividing the solubility of the product by the solubility of MA and the $P_{\text {app }}$ of the products by the $P_{\text {app }}$ of the MA).

\section{CONCLUSIONS}

The importance of increasing the water solubility of drugs belonging to BCS II class is well known. In the case of MA, besides increasing the biopharmaceutical properties of the drug using hydrophilic auxiliary substances, the severe adverse effects can be also 
reduced in such formulations. Water-solubility increasing auxiliary substances may modify the permeability of different APIs. In this work, different formulations of MA were tested and the relationship between solubility and permeability was evaluated. MA was embedded in the PEG 6000 polymer in the presence of sucrose ester surfactants. Based on the dissolution test results, confirmed by the Gompertz-function parameters, the best results were obtained in the case of the $10 \% \mathrm{D}-1216$ - containing product. This product also proved to be one of the best formulations in the cellular toxicity test on Caco-2 cells. The dissolved amount of MA after 120 min increased only moderately, but after 30 minutes a significant rise in the solubility of MA can be observed. Therefore, under in vivo conditions the higher dissolved amount of MA - which is available for absorption - may increase the absorption rate of MA.

Acknowledgments. - This paper was published under the framework of the European Social Found, Human Resources Development Operational Programme 2007-2013, Project No. ** POSDRU/159/1.5/S/133377.

\section{REFERENCES}

1. S. C. Sweetman (Ed.), Martindale: The Complete Drug Reference, $36^{\text {th }}$ ed., Pharmaceutical Press, London 2009, p. 80.

2. M. Batt, Non-coeliac flat jejunal mucosa, Gut 30 (1989) 67-68.

3. T. Hamaguchi, D. Shinkuma, Y. Yamanaka and N. Mizuno, Bioavailability of mefenamic acid: influence of food and water intake, J. Pharm. Sci. 75 (1986) 891-893.

4. J. L. Wallace, Mechanisms, prevention and clinical implications of nonsteroidal anti-inflammatory drug-enteropathy, World J. Gastroenterol. 19 (2013) 1861-1876; DOI: 10.3748/wjg.v19.i12.1861.

5. D. V. Derle, M. Bele and N. Kasliwal, In vitro and in vivo evaluation of mefenamic acid and its complexes with $\beta$-cyclodextrin and HP- $\beta$-cyclodextrin, Asian J. Pharm. 2 (2008) 30-34; DOI: 10. 4103/0973-8398.41562.

6. G. L. Amidon, H. Lennernas, V. P. Shah and J. R. Crison, A theoretical basis for a biopharmaceutic drug classification: the correlation of in vitro drug product dissolution and in vivo bioavailability, Pharm. Res. 12 (1995) 413-420.

7. D. Mudit, Y. Bhardwaj, P. K. Keshavarao and P. Selvam, Enhancing solubility and dissolution of mefenamic acid by freeze drying using $\beta$-cyclodextrin, Int. Res. J. Pharm. 2 (2011) 146-150; DOI: http://dx.doi.org/10.1590/S1984-82502011000400011.

8. U. Domanska, A. Pelczara and A. Pobudowska, Effect of 2-hydroxypropyl- $\beta$-cyclodextrin on solubility of sparingly soluble drug derivatives of anthranilic acid, Int. J. Mol. Sci. 12 (2011) 2383-2394; DOI: $10.3390 /$ ijms12042383.

9. I. Fülöp, Á. Gyéresi and Ș. Hobai, Characterisation of the interaction between fenamates and hydroxy-propyl- $\beta$-cyclodextrin, Bull. Med. Sci. 83 (2010) 58-62.

10. K. R. Rao, M. V. Nagabhushanam and K. P. Chowdary, In vitro dissolution studies on solid dispersions of mefenamic acid, Indian J. Pharm. Sci. 73 (2011) 243-247; DOI: 10.4103/0250-474X.91575.

11. G. Owusu-Ababio, N. K. Ebube, R. Reams and M. Habib, Comparative dissolution studies for mefenamic acid-polyethylene glycol solid dispersion systems and tablets, Pharm. Dev. Technol. 3 (1998) 405-412; DOI: 10.3109/10837459809009868.

12. A. Dahan A and J. M. Miller, The solubility-permeability interplay and its implications in formulation design and development for poorly soluble drugs, AAPS J. 14 (2012) 244-251; DOI: 10.1208/ s12248-012-9337-6. 
13. A. Beig, R. Agbaria and A. Dahan, Oral delivery of lipophilic drugs: The tradeoff between solubility increase and permeability decrease when using cyclodextrin-based formulations, Plos One 8 (2013) e68237; DOI: 10.1371/journal.pone.0068237.

14. G. E. Amidon, W. I. Higuchi and N. F. Ho, Theoretical and experimental studies of transport of micelle-solubilized solutes, J. Pharm. Sci. 71 (1982) 77-84.

15. J. M. Miller, A. Beig, R. A. Carr, G. K. Webster and A. Dahan, The solubility-permeability interplay when using cosolvents for solubilization: revising the way we use solubility-enabling formulations, Mol. Pharm. 9 (2012) 581-590; DOI: 10.1021/mp200460u.

16. A. Beiq, J. M. Miller and A. Dahan, Accounting for the solubility-permeability interplay in oral formulation development for poor water solubility drugs: the effect of PEG-400 on carbamazepine absorption, Eur. J. Pharm. Biopharm. 81 (2012) 386-391; DOI: 10.1016/j.ejpb.2012.02.012.

17. L. Kiss, E. Hellinger, A. M. Pilbat, A. Kittel, Z. Török, A. Füredi, G. Szakács, S. Veszelka, P. Sipos, B. Ózsvári, L. G. Puskás, M. Vastag, P. Szabó-Révész and M. A. Deli, Sucrose esters increase drug penetration, but do not inhibit P-glycoprotein in Caco-2 intestinal epithelial cells, J. Pharm. Sci. 103 (2014) 3107-3119; DOI: 10.1002/jps.24085.

18. A. Szüts and P. Szabó-Révész, Sucrose esters as natural surfactants in drug delivery systems - a mini-review, Int. J. Pharm. 433 (2012) 1-9; DOI: 10.1016/j.ijpharm.2012.04.076.

19. T. Hladon, J. Pawlaczyk and B. Szafran, Stability of mefenamic acid in the inclusion complex with $\beta$-cyclodextrin in the solid phase, J. Incl. Phenom. Macrocycl. Chem. 35 (1999) 497-506; DOI: 10.1023/ A:1008048612736.

20. Ryoto Sugar Ester Technical Information, Ryoto Sugar Ester (Food grade)/ Surfhope ${ }^{\mathrm{TM}}$ SE Pharma, Mitsubishi-Kagaku Foods Corporation; http://www.mfc.co.jp/english; last access date May 25, 2015.

21. A. Szüts, E. Pallagi, G. Regdon, Jr., Z. Aigner and P. Szabó-Révész, Study of thermal behaviour of sugar esters, Int. J. Pharm. 336 (2007) 199-207; DOI: 10.1016/j.ijpharm.2006.11.053.

22. A. Szüts, Zs. Makai, R. Rajkó and P. Szabó-Révész, Study of the effects of drugs on the structures of sucrose esters and the effects of solid-state interactions on drug release, J. Pharm. Biomed. Anal. 48 (2008) 1136-1142; DOI: 10.1016/j.jpba.2008.08.028.

23. European Pharmacopoeia $8^{\text {th }}$ ed., Council of Europe, Strasbourg 2013, pp. 288-295.

24. Y. Zhang, M. Huo, J. Zhou, A. Zou, W. Li, C. Yao and S. Xie, DDSolver: an add-in program for modeling and comparison of drug dissolution profiles, AAPS J. 12 (2010) 263-271; DOI: 10.1208/ s12248-010-9185-1.

25. P. Costa and J. M. Sousa Lobo, Modeling and comparison of dissolution profiles, Eur. J. Pharm. Sci. 13 (2001) 123-133; DOI: 10.1016/S0928-0987(01)00095-1.

26. I. Fülöp, Á. Gyéresi, M. A. Deli, L. Kiss, M. D. Croitoru, P. Szabó-Révész and Z. Aigner, Ternary solid dispersions of oxicams: Dissolution and permeability study, Farmacia 63 (2015) 286-295.

27. M. Dixit, A. Kini and P. K. Kulkarni, Enhancing the dissolution of polymorphs I and II of mefenamic acid by spray drying, Turk. J. Pharm. Sci. 9 (2012) 13-26.

28. S. Romero, B. Escalera and P. Bustamante, Solubility behavior of polymorphs I and II of mefenamic acid in solvent mixtures, Int. J. Pharm. 178 (1999) 193-202.

29. S. G. Vijaya Kumar and D. N. Mishra, Preparation, characterization and in vitro dissolution studies of solid dispersion of meloxicam with PEG 6000, Yakugaku Zasshi (J. Pharm. Sci. Japan) 126 (2006) 657-664.

30. H. Lokhandwala, A. Deshpande and S. Deshpande, Kinetic modelling and dissolution profiles comparison: an overview, Int. J. Pharm. Biol. Sci. 4 (2013) 728-737. 